\title{
A universidade e a crise da educação
}

\author{
Paulo Renato Souza
}

\section{UM QUADRo Difícil E EM DETERIORAÇĀo}

A crise da educação no Brasil avança de modo claro e preocupante desde meados dos anos 70. Na primeira metade dos anos 80, no embalo dos ares reformistas iniciais da "Nova República" e de ações de vários governadores eleitos em 1982 depois de longos anos de jejum político, parecia que essa tendência seria revertida definitivamente. Se aqueles esforços tivessem tido continuidade, não tenho dúvidas de que estaríamos hoje analisando uma realidade menos crítica e com perspectivas menos ruins. Não foi o que ocorreu. Os governos estaduais não deram, em geral, continuidade ao esforço de recuperação da educação; o governo Sarney, por seu turno, acabou abandonando qualquer veleidade de conduzir um verdadeiro processo de melhoria do sistema educacional, absorvido pelo dia-a-dia da administração turbulenta do sistema universitário federal.

As tendências negativas da queda na qualidade do ensino público de $1^{\circ}$ e $2 \%$ graus, de desestímulo e má remuneração de professores, a manutenção dos altos índices de repetência e evasão, a impossibilidade de eliminar o analfabetismo e o enorme contingente de crianças fora da escola parecem assim consolidar-se de forma definitiva. Ganha-se a consciência, por outro lado, de que os problemas não são superáveis com a simples mudança na intenção de atuar dos dirigentes, como romanticamente chegou-se a postular no começo dos anos 80.

No nível universitário, as tendências são levemente diferentes, mas também preocupantes. Por uma parte, as melhores universidades do país, pertencentes ao sistema público estadual de São Paulo, estavam em crise no começo dos anos 80 , claramente se recuperam a partir de 1983 e ingressam em uma etapa de renovação e cooperação que se manteve ao longo de toda a década. De outra parte, observamos que as escolas federais começam a revelar suas virtudes e fraquezas de forma bastante clara nesses anos 80. Aparece um quadro preocupante que requer uma profunda alteração de rumos, se quisermos aspirar a contar com um sistema público importante para o desenvolvimento do país nos próximos anos. O outro segmento do terceiro grau, o setor privado, não mostrou evolução no decênio. $O$ que já era bom ou razoável continuou sendo, dentro de um enorme conjunto de escolas de qualidade muito baixa e que satisfazem apenas às exigências do credencialismo da sociedade brasileira.

Na área universitária deve-se registrar, contudo, um avanço significativo na pós-graduação, concentrada nas melhores universidades estaduais e federais. Criou-se a pesquisa universitária no país e intensificou-se o debate e o diálogo entre as instituições.

No seu conjunto o sistema educacional apresenta uma estrutura de funcionamento dicotômica em que operam dois circuitos: um circuito "virtuoso" que passa pelas escolas particulares de $1^{\circ}$ e $2^{\circ}$ graus e pelo sistema público de 3 o grau; e um circuito "vicioso" que opera nas escolas públicas de $1^{\circ}$ e $2^{\circ}$ graus e na rede de faculdades e universidades particulares de baixa qualidade.
PAULO RENATO SOUZA é professor titular do Instituto de Economia da Unicamp (Universidade de Campinas), com mestrado pela Universidade do Chile e doutorado pela Unicamp. Foi reitor da Unicamp de 1986 a 1989, secretário de Educação do Estado de São Paulo (84-86). É autor de Emprego, salário e pobreza e Quem paga a conta?

Dívida, déficit e inflação nos anos 80 , entre outros.

\section{Dezembro \\ Janeiro \\ Fevereiro} $1990-1991$

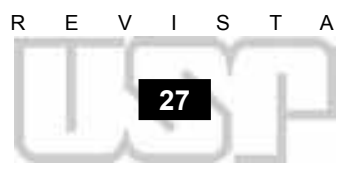


$\mathrm{O}$ quadro atual, mantida a inércia das tendências recentes, não apresenta a menor chance de reversão. Ao contrário, podemos esperar apenas uma piora nos próximos tempos, pois a falta de comunicação e intercâmbio no conjunto do sistema não permite que sejam superados os enormes abismos de qualidade hoje existentes. Do ponto de vista da sociedade brasileira e de seu desenvolvimento é indispensável a superação dessa heterogeneidade. De muito pouco nos servirá contarmos com um pequeno segmento de boa qualidade no sistema educacional se a sua maior parte continuar a operar restrita aos limites daquele circuito vicioso. A educação deixará de cumprir o papel integrador da comunidade e formador do cidadão de uma só nação. Como conseqüência, a tendência desruptiva da educação se implantará na própria sociedade. Em outras palavras, o desenvolvimento da sociedade brasileira requer a mudança radical nas tendências de evolução do sistema educacional.

\section{DESAFIOS E OPORTUNIDADES}

O resgate do sistema educacional brasileiro passa por um conjunto de ações de reforma interna, redefinição de carreiras, estímulo à qualificação, maior volume e continuidade nos fluxos de recursos investidos, definição de prioridades, etc. Não pretendo analisar ou formular o que seria um plano global de recuperação da educação. Quero porém destacar um aspecto que me parece essencial: o papel que a universidade deve cumprir nesse processo.

$\mathrm{O}$ fato de contarmos com um segmento de boa qualidade dentro do sistema educacional oferece, a meu ver, uma oportunidade única que pode facilitar o caminho da recuperação do conjunto. Trata-se de fazer com que a boa qualidade que aí existe se derrame sobre o conjunto do sistema, tanto de nível universitário, quanto de $1^{\circ}$ e $2^{\circ}$ graus.

A reforma do sistema universitário brasileiro deve partir da constatação de que estamos diante de um conjunto extremamente heterogêneo de instituiçōes. Essa heterogeneidade abrange todas as dimensões da vi ta acadêmica, e acabou verificando-se a despeito da norma legal que promoveu o modelo único de universidade onde a indissociabilidade entre ensino e pesquisa deveria observar-se em nível de cada instituição. Essa heterogeneidade precisa ser reconhecida na legislação e na política educacional como condição para ser superada.

É preciso resgatar algumas experiências vividas dentro do sistema universitário como base para inspirar a redefinição do sistema dentro da perspectiva de transformação do sistema educacional no seu conjunto. Tenho defendido a idéia de que partindo do princípio da qualidade e da responsabilidade social, nossas instituições de ensino superior poderão organizar-se com maior liberdade a partir de algumas diretrizes mínimas e indispensáveis, definidas em nível nacional: algumas instituições serão universidades "tout court", ao passo que outras serão formadoras de profissionais (sem maior preocupação com a pesquisa), enquanto outras ainda poderão dedicar-se à pesquisa e não ao ensino. Para tanto a própria legislação deveria definir um sistema de ensino superior que contemplasse numa estrutura matricial vários tipos de instituições e vários níveis de especialização para cada uma delas.

No campo da especialização das instituições deveríamos prever várias possibilidades dentro de quatro áreas de opção:

a. ênfase diversa entre ensino e pesquisa;

b. ênfase diversa entre tipos de ensino: graduação, pós-graduação e extensão;

c. ênfase no ensino geral ou especialização no ensino tecnológico;

d. possibilidade real de associação com instituições do sistema de ciência e tecnologia que não desenvolvem atividades de ensino.

Num sistema como esse seria essencial contemplar na própria legislação os mecanismos que viabilizassem e garantissem a articulação entre todas as instituições do ensino superior. Obteríamos assim a indissociabilidade entre ensino, pesquisa e extensão no nível do conjunto do sistema e não em cada instituição. $O$ objetivo central que está por trás da idéia de indissociabilidade estaria plenamente atingido tanto na pesquisa quanto no ensino e na extensão.

Entre instituições de natureza diferente poderão estabelecer-se convênios de cooperação de modo que uma universidade mais desenvolvida colabore na implantação e no desenvolvimento de programas em outra instituição, envolvendo treinamento de docen- 

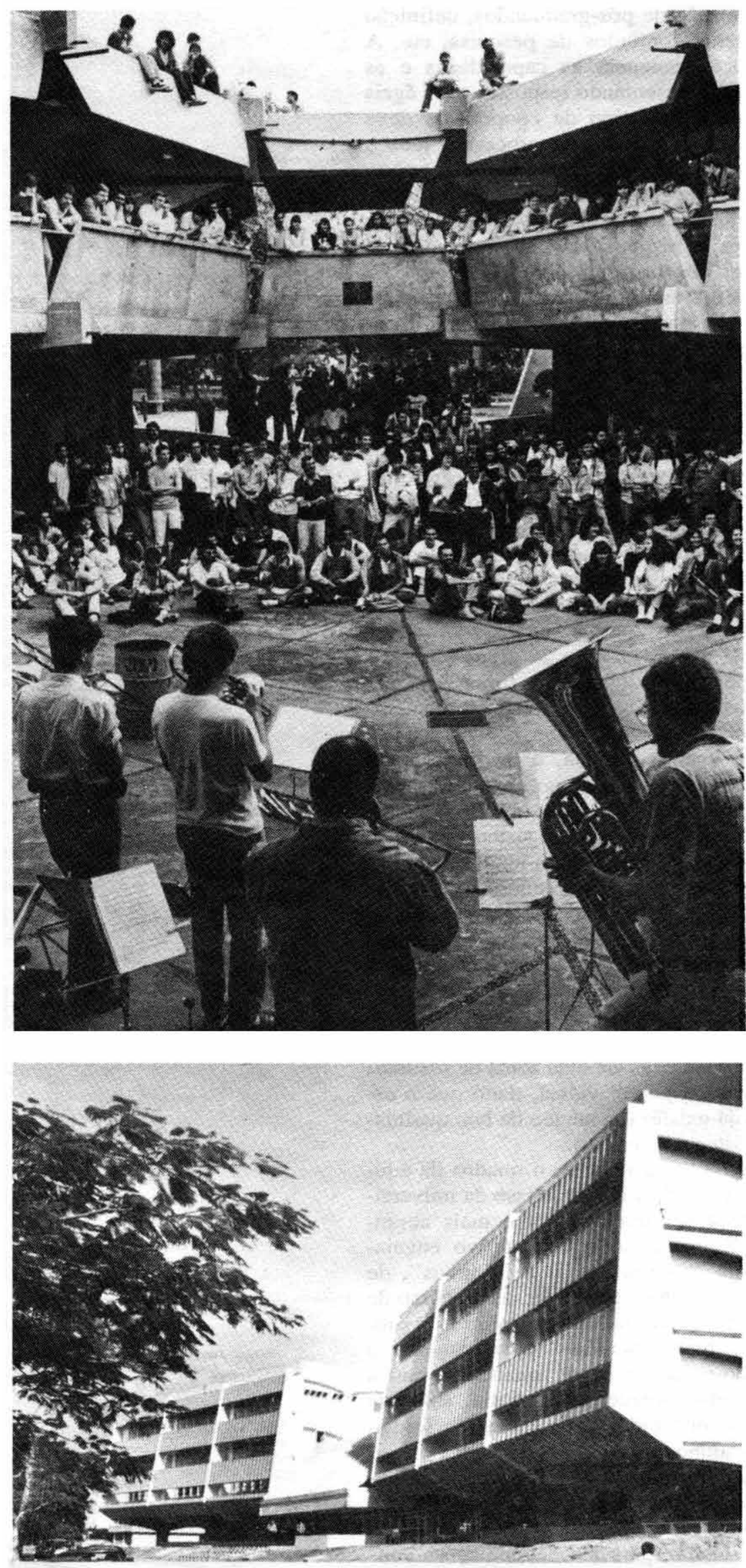

cretas atuais, chegar a uma universidade capaz de cumprir esse papel essencial? É óbvio que é impossível, no âmbito de um artigo, contemplar toda a gama de situações iniciais para discutir os avanços necessários, dada a grande heterogeneidade, considerando apenas o universo do sistema público. Valendo-me da recente experiência de ter dirigido a Universidade de Campinas nos últimos quatro anos, me permito assinalar algumas liçōes que aprendi (e tentei colocar em prática), e que justamente apontam na direçāo de conduzir a universidade e cumprir aquilo que me parece é o seu papel no desenvolvimento da sociedade.

\section{A UNIVERSIDADE EM SI}

Creio que os objetivos centrais da atuação da universidade - e também, portanto, os critérios centrais para avaliá-la - devem ser dois: a busca da qualidade acadêmica, de um lado, e o grau de vinculação ou conexão com a sociedade na qual se insere e que lhe dá sustentação, de outro. Em relação ao primeiro objetivo não há muita discussão: mesmo inserida num país do terceiro mundo, mesmo sustentada por uma sociedade que apresenta ainda carências bem elementares para parcelas significativas do seu todo, a universidade deve buscar o seu valor universal - a qualidade acadêmica. Apesar de termos ainda um longo caminho a percorrer na universidade brasileira na direção de seu aperfeiçoamento acadêmico, não me deterei na análise deste ponto, pois é mais conhecido e aceito como valor universitário. Assim, trata-se de uma questão de definir e pôr em prática os mecanismos que estimulem a busca de qualidade dentro de nossas instituiçōes de ensino superior, o que desde logo não é trivial.

O segundo objetivo ou critério de avaliação da universidade requer uma discussão maior, até mesmo porque é mais abstrato. Creio que um dos defeitos essenciais da universidade brasileira é justamente sua desconexão da realidade do país. Pior que isso, sequer existe a consciência de que a universidade deve contas à sociedade e que deve estar comprometida com o seu dia-adia, com o seu desenvolvimento e com o bem-estar da maioria de sua população. Em outras palavras, o trabalho que se realiza dentro da universidade deve ser pertinente e ter conseqüências concretas para o desenvolvimento da sociedade, ainda mais e especialmente no caso das instituiçōes públicas, sustentadas pelo dinheiro dos impostos - arrecadado, diga-se de passagem, através

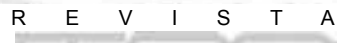




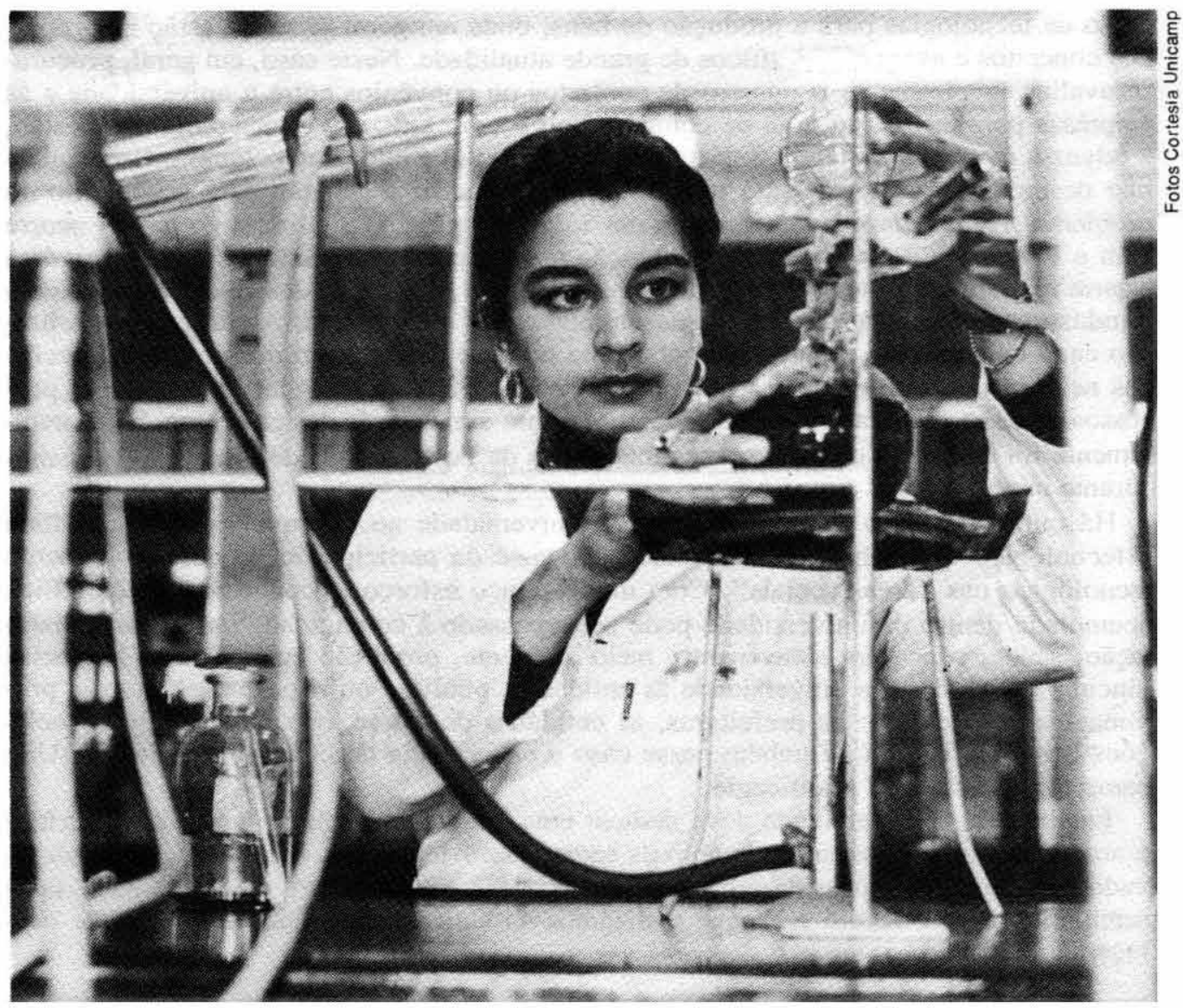

de um sistema tributário essencialmente injusto.

Pode-se argumentar que ao formar os alunos nas várias áreas do conhecimento a universidade realiza justamente esse compromisso social. Essa, aliás, parece-me ser a idéia ou a visão que implicitamente informa a opinião da maioria das pessoas. É claro que uma parte do compromisso social se realiza através do ensino e por isso justamente ele deve ser de boa qualidade e inserido na realidade do país em termos de cursos oferecidos, das vagas disponíveis e do próprio conteúdo ministrado. Contudo, o ensino é apenas uma parte do trabalho acadêmico. Tão importante quanto o ensino dentro da universidade deveria ser a pesquisa e a extensão. Digo deveria porque infelizmente essa não é a realidade na imensa maioria das universidades brasileiras, mesmo nas públicas; isto apesar de a maioria de seus professores ser remunerada em regime de dedicação integral ao ensino e à pesquisa, em que as horas semanais de pesquisa são supostamente maiores que as de ensino.

Na pesquisa e na extensão, o compromisso da universidade deve ser com o desenvolvimento científico e tecnológico da sociedade. Isto significa um envolvimento com todos os agentes sociais através dos quais se verifica o processo de desenvolvimento da sociedade, o governo, as empresas, as entidades da sociedade civil, as associaçōes comunitárias, etc.

Se vivemos em uma sociedade capitalista, organizada com base na empresa privada, obviamente o relacionamento da universidade, mesmo pública, deve incluir também o intercâmbio e o trabalho conjunto com a empresa privada. Entretanto, também aqui há exageros nas avaliaçōes tanto de defensores quanto de opositores à idéia da contribuição positiva da universidade ao desenvolvimento tecnológico através de contratos com empresas privadas. $\mathrm{O}$ exagero consiste em entender que essa é a forma essencial ou mais importante de relacionamento da universidade com a sociedade, e que como tal deva ser buscada com absoluta prioridade e quase exclusividade. Para colocar o problema nos seus devidos termos, vamos restringir por um momento a análise a uma questão específica da contribuição ao desenvolvimento tecnológico strictu sensu: à ge-
Na outra página, acima, show de alunos na Unicamp; vista da Biblioteca Central; acima, foto do laboratório de Química da mesma universidade

\section{Dezembro Janeiro Fevereiro} 1990-1991 
ração de tecnologias para a produção de bens, onde em geral se supõe estão incorporados conceitos e avanços científicos de grande atualidade. Neste caso, em geral, procurase avaliar simplesmente o número de contratos ou convênios entre a universidade e as empresas para medir seu grau de compromisso social. Ora, isto é uma parte da questão, e talvez a menos importante. Serve, contudo, para um efeito promocional interessanté e não desprezível, especialmente quando se quer chamar a atenção para o conjunto do problema. Num país que precisa dar um salto tecnológico significativo, como ocorre com o Brasil nos dias atuais, a contribuição mais importante da universidade nessa área estaria na definição, junto com os responsáveis pela política de desenvolvimento e com a indústria, da política nacional de desenvolvimento tecnologico. A partir dessa definição cada universidade atuaria concretamente no desenvolvimento dos projetos específicos necessários para a execução da política tecnológica até alcançar os produtos e processos a serem repassados para a indústria, agora sim através das empresas. Esse precisamente foi o sentido dos Programas Integrados de Pesquisa que definimos na Unicamp durante minha gestão.

Há outra dimensão da contribuição da universidade ao desenvolvimento científico e tecnológico que é bastante esquecida. Trata-se da participação no desenvolvimento tecnológico nas "áreas sociais". Com muito pouco esforço, o conhecimento científico acumulado dentro da universidade pode ser repassado à comunidade nas áreas de habitação, saúde, educação, saneamento, meio ambiente, produção cultural, etc. É preciso vincular, neste caso, a universidade às entidades, públicas ou não, que estão mais próximas da comunidade: as prefeituras, as entidades de classe, os sindicatos, as associações comunitárias, etc. Também nesse caso a experiência desenvolvida dentro da Unicamp foi importante e gratificante.

Finalmente, a universidade deve dedicar uma grande importância à reflexão, à crítica e ao debate sobre o desenvolvimento da sociedade. Além disso, esse debate deve ser levado para fora dos muros da universidade. Este foi, por exemplo, o sentido da série de seminários Brasil Século XXI que realizamos na Unicamp sobre as tendências de evolução do paŕs a longo prazo.

\section{Poder Público e Universidade}

Existe muito desperdício dentro da universidade brasileira. Os dados comparativos, utilizando as relações professor/aluno, funcionário/aluno, número de anos para conclusão de curso, etc., com a situação em outros países mais avançados, mostram invariavelmente uma situação altamente desfavorável para nós. Há também uma sensação muito clara de que poderíamos realizar mais com os mesmos recursos de que dispomos ou com pouco a mais. Isso é particularmente verdadeiro para o sistema público federal, mas é aplicável também às melhores universidades do sistema estadual paulista.

Essa constatação tem levado inúmeras vezes as autoridades, tanto em nível federal quanto estadual, à conclusão de que é preciso diminuir os recursos à disposição da universidade. Por vezes essa diminuição é realizada em termos de cortes salariais, por vezes em termos de drástica redução nos recursos de custeio e investimento, chegando-se mais recentemente até mesmo à proposta de corte de um certo percentual no número de professores e/ou funcionários. Essa me parece uma visão tacanha da questão da universidade e da própria questão educacional no país.

Se existe desperdício, isso apenas demonstra que é possível exigir maiș da universidade em sua contribuição à sociedade. Em outras palavras, demonstra-se que o importante papel que a universidade poderia cumprir para superar a crise da educação no Brasil e tornar mais efetiva sua presença na sociedade brasileira poderia ser alcançado sem grandes custos adicionais, apenas pela mobilização e engajamento da universidade. Por outro lado, creio que seria também tacanho imaginar que essa maior contribuição deveria dar-se prioritariamente pelo aumento do número de vagas na graduação. Pareceme que a universidade tem um potencial infinitamente maior e que deveria expressar-se em formas inovadoras de articulação com a sociedade.

Obviamente tudo isso não depende apenas da universidade. A condição preliminar é a de que a própria sociedade tome algumas decisões de sua política maior através de suas instâncias de governo, que fixa suas prioridades de desenvolvimento tanto no âmbito econômico, quanto social. Infelizmente não temos assistido a ações, quer no âmbito federal, quer no estadual, que signifiquem a definição de políticas de médio e longo prazo que requeiram a participação concreta da universidade. 